\title{
Erratum to: The safety of long-term cryopreservation on slow-frozen early cleavage human embryos
}

\author{
Qinli Liu ${ }^{1,2,3}$ - Ying Lian ${ }^{1,2,3}$ - Jin Huang ${ }^{1,2,3} \cdot$ Xiulian Ren ${ }^{1,2,3} \cdot \operatorname{Ming} \operatorname{Li}^{1,2,3}$ • \\ Shengli Lin ${ }^{1,2,3} \cdot$ Ping Liu ${ }^{1,2,3} \cdot$ Jie Qiao ${ }^{1,2,3}$
}

Published online: 24 March 2015

(C) Springer Science+Business Media New York 2015

Erratum to: J Assist Reprod Genet (2014) 31:471-475

DOI 10.1007/s10815-014-0197-0

The original version of this article unfortunately contained a mistake. The word "equally" is missing in the article note, and should read "Qinli Liu and Ying Lian contributed equally to this work."

The online version of the original article can be found at http://dx.doi.org/ 10.1007/s10815-014-0197-0.

\footnotetext{
Ping Liu

bysylp@sina.com

1 Reproductive Medical Centre, Department of Obstetrics and Gynecology, Peking University Third Hospital, Beijing, China

2 Key Laboratory of Assisted Reproduction, Ministry of Education, Beijing, China

3 Beijing Key Laboratory of Reproductive Endocrinology and Assisted Reproduction, Beijing, China
} 